\title{
First direct observations of the reduced striations at pump frequencies close to the electron gyroharmonics
}

\author{
F. Honary ${ }^{1}$, T. R. Robinson ${ }^{2}$, D. M. Wright ${ }^{2}$, A. J. Stocker ${ }^{2}$, M. T. Rietveld ${ }^{3}$, I. McCrea ${ }^{4}$ \\ ${ }^{1}$ Communications Research Centre, Faculty of Applied Sciences, Lancaster University, Lancaster, UK \\ ${ }^{2}$ Department of Physics and Astronomy, University of Leicester, Leicester, UK \\ ${ }^{3}$ EISCAT, N-9027 Ramfjordbotn, Norway \\ ${ }^{4}$ Rutherford Appleton Laboratory, Chilton, Didcot, Oxon, OX11 0QX, UK
}

Received: 5 January 1999 / Revised: 14 April 1999 / Accepted: 16 April 1999

\begin{abstract}
It is well known that the ionospheric plasma response to high-power HF radio waves changes drastically as the heater frequency approaches harmonics of the electron gyrofrequency. These include changes in the spectrum of the stimulated electromagnetic emission, reduction in the anomalous absorption of low-power diagnostic waves propagating through the heated volume, and reduction in the large scale F-region heating. Theoretical models as well as previous experimental evidence point towards the absence of small-scale fieldaligned plasma density irregularities at pump frequencies close to electron gyroharmonics as the main cause of these changes. Results presented in this paper are the first direct observations of the reduced striations at the 3rd gyroharmonic made by the CUTLASS radar. In addition, simultaneous EISCAT observations have revealed that the "enhanced ion-line" usually present in the EISCAT ion-line spectrum during the first few seconds after heater switch on, persisted at varying strengths while the heater was transmitting at frequencies close to the 3 rd electron gyroharmonics.
\end{abstract}

Key words. Ionosphere (active experiments; ionospheric irregularities) · Radio science (ionospheric physics)

\section{Introduction}

In this paper we report new experimental findings concerning the suppression of the small-scale fieldaligned irregularities when the heater frequency is near the third harmonic of the electron gyrofrequency. One of the most important phenomena discovered during

Correspondence to: F. Honary

e-mail: F.Honary@lancaster.ac.uk ionospheric modification experiments by means of high-power HF radio waves was the generation of small-scale field-aligned irregularities (striations) and their close connections to the anomalous absorption of low-power HF waves passing through the heated volume (Jones et al., 1982, 1983; Robinson, 1989) and to high frequency stimulated electromagnetic emission (SEE) (Thidé et al., 1982; Boiko et al., 1985; Stubbe et al., 1994; Stocker et al., 1993; Honary et al., 1995).

Striations are local stationary depletions of plasma density, with scales of the order of a few meters across and several kilometres along the magnetic field lines. A theoretical picture for the formation and maintenance of striations is described by Dysthe et al. (1982), Mjølhus (1993, 1997), Vaskov and Gurevich (1984), and Gurevich et al. (1995). In all these theories, a preexisting striation will lead to generation of upper hybrid waves which are trapped in the density depletion of the individual striation, leading to local heating of the ionospheric plasma and thereby increasing the density depletion by plasma transport along the field lines.

Modification experiments in which the heater operates at frequencies in the vicinity of the harmonics of the electron gyrofrequency, has been the focus of recent studies. The first measurements were primarily concerned with the changes that occurred in the spectrum of the SEE. The SEE spectrum has a rich structure, extending more than $100 \mathrm{kHz}$ around the pump frequency. Whereas some of the SEE features exist at pump frequencies away from the gyroharmonics, the so-called "universal features", others only exist when pump frequency is at or very close to gyroharmonics: the "gyro features" (Leyser et al., 1989, 1990, 1994; Stubbe et al., 1984, 1994; Honary et al., 1995). Combined anomalous absorption and SEE measurements, involving systematic pump frequency changes around the vicinity of gyroharmonics have indicated that the universal features are physically connected with each other via striations (Stocker et al., 1993; Stubbe et al., 1994; Stubbe 1996). 


\section{Experimental arrangement}

The observations reported in this paper are from the UK heating campaign in April 1997. The heater, which is located at Ramfjordmoen about $16 \mathrm{~km}$ to the Southeast of Tromsø, Norway, has been described in the literature (Rietveld et al., 1993). The heater transmitted along the local magnetic field line with an effective radiated power (ERP) of $100 \mathrm{MW}$ and O-mode polarisation. The heater frequency was kept for a few cycles of $2 \mathrm{~min}$ on, followed by $2 \mathrm{~min}$ off at $4.10 \mathrm{MHz}$, and then changed to $4.05 \mathrm{MHz}$ at 12:18 UT, for a few cycles. The heater was finally switched back to 4.10 MHz at 12:42 UT for the last few cycles of the experiment. The times of frequency changes are marked by dashed line across the first two panels and each heater-on time is marked at the top of the first panel in Fig. 1.

The spectrum analyser employed for the real time recording of SEE spectra was located at Seljelvnes about $40 \mathrm{~km}$ south of Tromsø. The other diagnostics employed in this experiment are CUTLASS and EISCAT UHF radar.

CUTLASS is a bistatic HF coherent radar, with stations in Finland and Iceland, and forms part of the international SuperDARN chain of HF radars (Greenwald et al., 1995). Each radar of the system is a frequency agile $(8-20 \mathrm{MHz})$ radar, routinely measuring the line-of-sight (l-o-s) Doppler velocity and spectral width of, and the backscattered power from, ionospheric plasma irregularities. The radars form 16 beams of separation 3.24 degrees. Each beam is gated into 75 range bins, each of length $45 \mathrm{~km}$ standard operations. During standard operations the dwell time for each beam is $7 \mathrm{~s}$, giving a full 16 beam scan, covering $52 \mathrm{~s}$ in azimuth and over $3000 \mathrm{~km}$ in range (an area of over $4 \times 106 \mathrm{~km}^{2}$ ), every $2 \mathrm{~min}$. Common-volume data from the two stations can be combined to provide convection velocities perpendicular to the magnetic field, although the interval under study utilises data only from the Finland radar. For the interval on 23 April 1997 the Finland radar was operating a non-standard scan mode. In this mode, rather than the usual sweep through beams $0,1,2, \ldots, 15$ the sequence $2,5,3,5,4,5, \ldots 8,5$ was employed, where beam 5 approximately overlies Tromsø. The dwell time on each beam was $1 \mathrm{~s}$ and the range resolution was increased to $15 \mathrm{~km}$. This allowed a narrow scan of the heated volume with high temporal and spatial resolution.

The EISCAT UHF antenna at Tromsø was fixed in the field-aligned direction. Four different modulations were transmitted, and all were received in such a way as to investigate the ion line at different height resolutions. For the E-region and lower F-region a high-resolution alternating code gave spectra at a range resolution of $3.15 \mathrm{~km}$. Independent measurements of raw electron density (scaled and range corrected power estimates) were made at the same resolution between heights of 86.8 and $271.4 \mathrm{~km}$. A longer pulse measured the raw electron density at a range resolution of $4.5 \mathrm{~km}$ between altitudes of $68.69 \mathrm{~km}$ and $415.8 \mathrm{~km}$, while a final low- resolution long pulse gave ion line spectra between heights of $150 \mathrm{~km}$ and $600 \mathrm{~km}$ at a resolution of $22.5 \mathrm{~km}$. The data were recorded at a time resolution of $5 \mathrm{~s}$.

\section{Observations}

Figure 1 presents simultaneous observations made by CUTLASS, EISCAT and the spectrum analyser as a function of time for an interval of $1 \mathrm{~h}$ between 12-13 UT on 23 April 1997. The first panel illustrates the CUTLASS backscatter power, in the second panel the EISCAT UHF observations of ion-line power profiles at four different heights close to the interaction region is depicted. The EISCAT UHF ion line is strongly enhanced for a few seconds after heater turn on at the so-called matching height. This is the level, usually a few $\mathrm{km}$ below the reflection height, where natural Langmuir waves at the frequency of the HF pump have k vectors matching those of the radar.

In the experiment reported here the height of the enhanced ion-line was close to $197 \mathrm{~km}$ for heater frequency of $4.05 \mathrm{MHz}$ and in the height range of 200-209 km for heater frequency of $4.10 \mathrm{MHz}$. Finally, the third panel in Fig. 1 presents three measurements of SEE features at three different times corresponding to different heater frequencies. The presence of a DownShifted Maximum (DM) in the SEE spectrum has been shown to be a very good indicator of whether the heater frequency is near to or far from a harmonic of the electron gyrofrequency.

The observations presented in Fig. 1 may be summarised as follows: CUTLASS backscatter power levels dropped from $30-35 \mathrm{~dB}$ at $4.1 \mathrm{MHz}$ right down to $<5$ $\mathrm{dB}$ at $4.05 \mathrm{MHz}-$ a power reduction of at least $30 \mathrm{~dB}$. This provides clear evidence of the greatly reduced fieldaligned irregularities at heater frequency of $4.05 \mathrm{MHz}$ which is believed to be close to the third harmonic of the electron gyrofrequency for the first three heater cycles at 4.05 MHz. However, due to the natural changes in the state of the ionosphere, during the last two cycles of the heater operating at the frequency of $4.05 \mathrm{MHz}$ it became apparent that the frequency of $4.05 \mathrm{MHz}$ no longer matched the third electron gyrofrequency.

EISCAT observations include power profiles of the ion-line as well as measurements of electron and ion temperatures and electron density. It was found that the enhanced ion line usually present in the EISCAT ionline spectrum during the first few seconds after heater switch on, persisted at varying strengths while the heater was transmitting at frequencies close to the third

Fig. 1. Data panels indicating, from the top (a) CUTLASS backscatter power, (b) EISCAT UHF observations of ion-line power profiles at four different heights close to the heater "matching height", both versus time, and (c) three measurements of SEE features at three different times corresponding to heater frequencies of $4.10 \mathrm{MHz}$, $4.05 \mathrm{MHz}$ and $4.10 \mathrm{MHz}$ from left to right respectively. The times of measurements are presented in the panels 


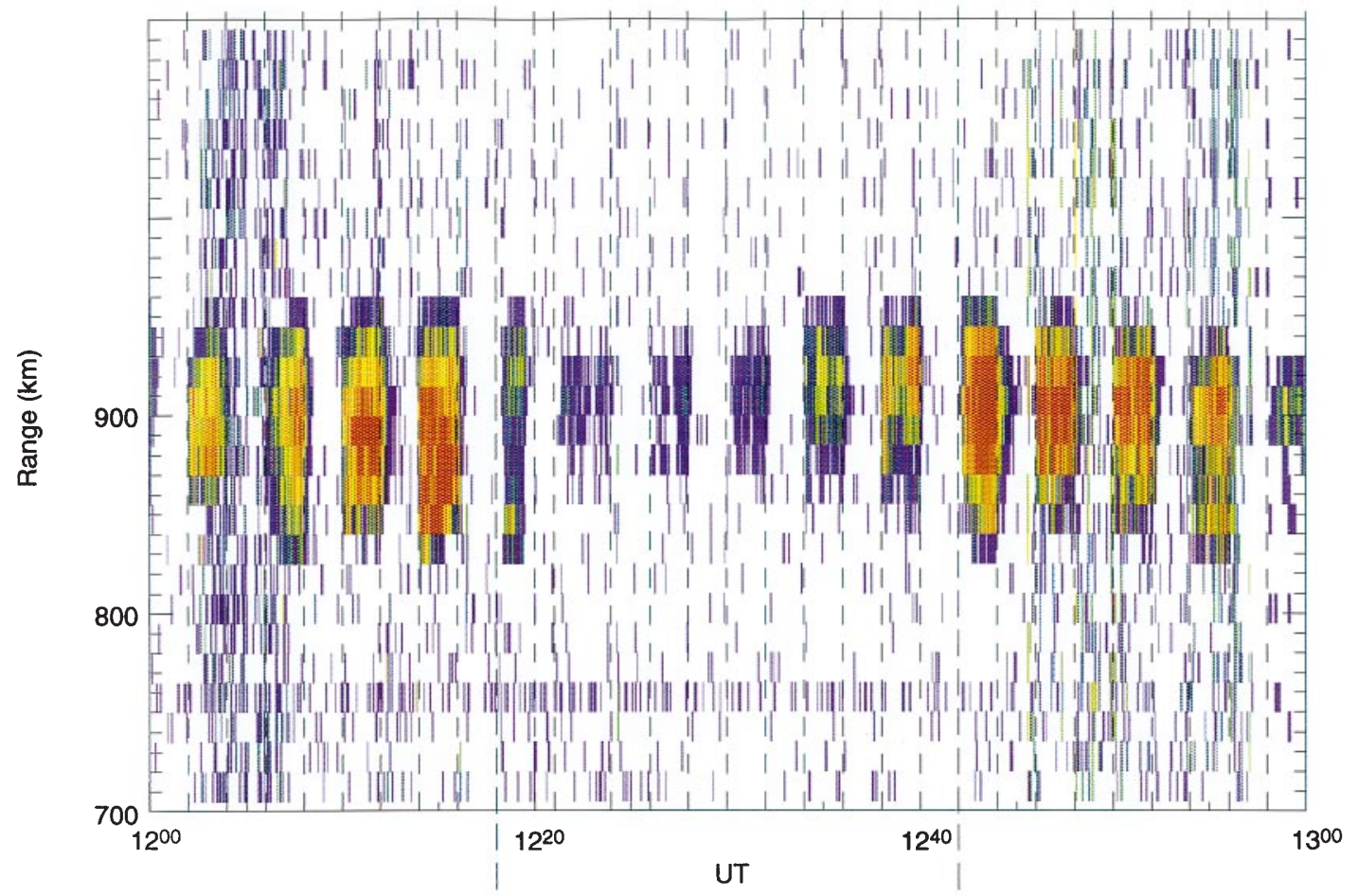

b

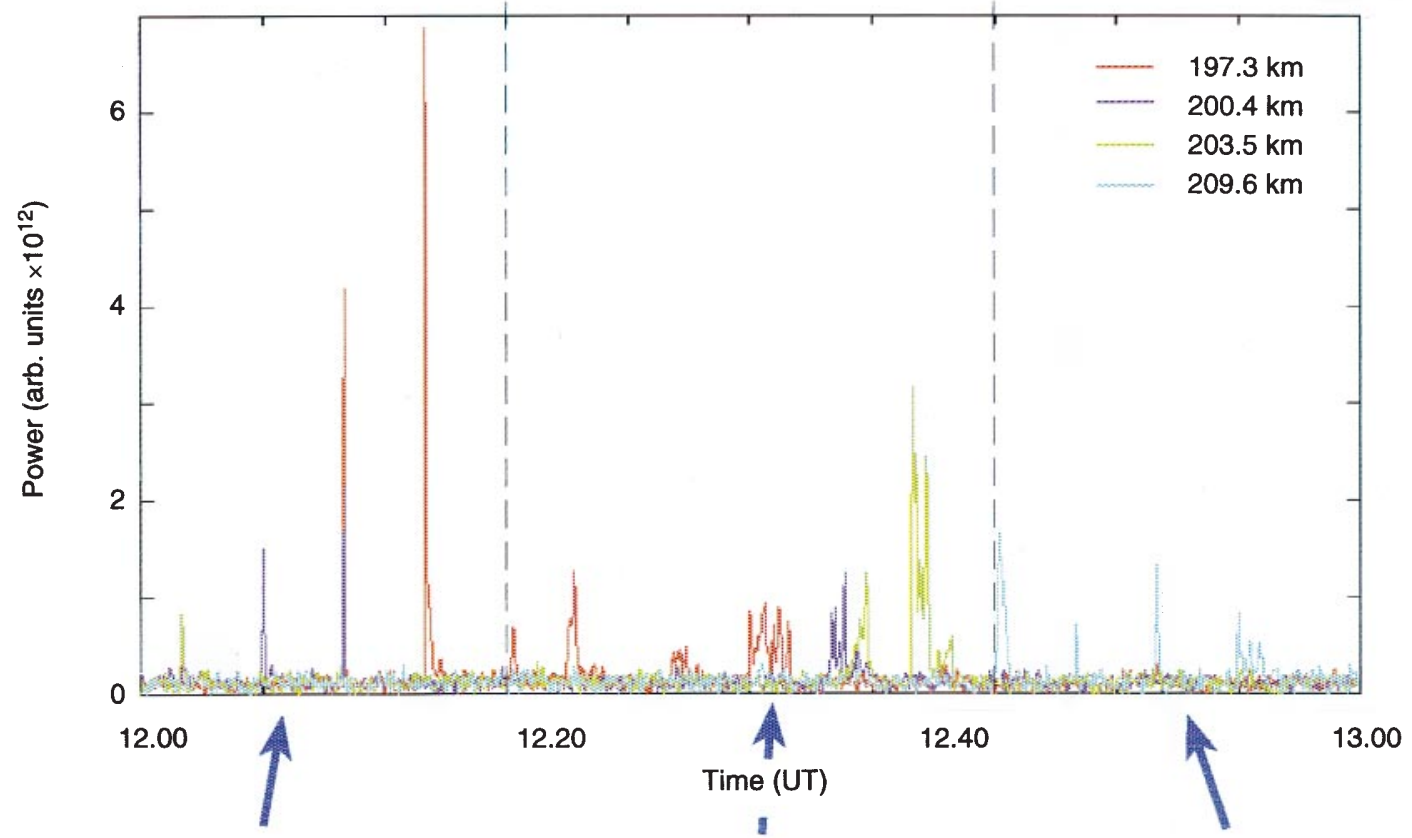

c

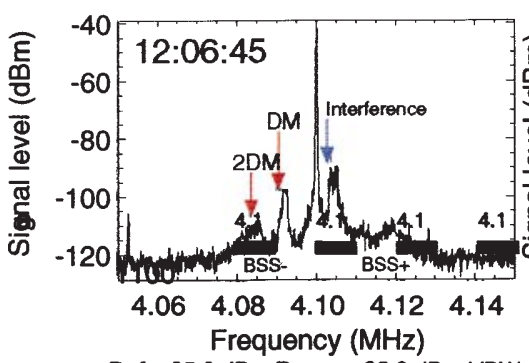

Ref:: $-35.0 \mathrm{dBm}$ Range: $-25.0 \mathrm{dBm}$ VBW: $100 \mathrm{~Hz}$ RBW: $100 \mathrm{~Hz}$

1000
Above
Gyroharmonic

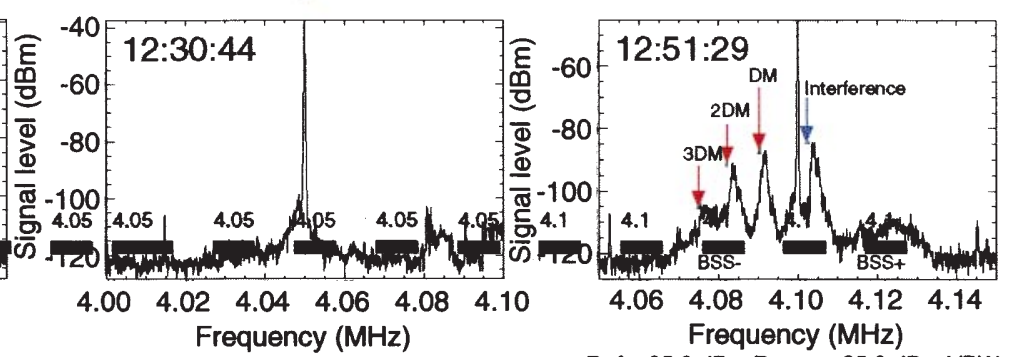

Ref.: $-35.0 \mathrm{dBm}$ Range: $-25.0 \mathrm{dBm}$ VBW: $100 \mathrm{~Hz}$ RBW: $100 \mathrm{~Hz}$

3rd Electron

Gyroharmonic
Above

Gyroharmonic 
electron gyroharmonic. It is the first time that the relation between heater-induced ion-line enhancement and the heater frequency has been reported. This is an interesting result which can be used to indicate if the heater frequency is close to the electron gyroharmonic, the same way as SEE features are employed in gyroheating experiments.

The enhanced ion line is associated with a similar plasma line enhancement, both of which are a manifestation of the parametric decay instability. The quenching of the enhancements within seconds of heater turn on (also known as the overshoot) has been explained in terms of Landau self-absorption, caused by the HFinduced electron temperature enhancement (Stubbe, 1996). The incoherent scatter spectrum becomes distorted when the enhanced ion-line is present, which makes temperature estimates unreliable in the narrow altitude range close to the heater reflection height. Although previous observation reported by Robinson et al. (1996) indicated substantial reduction in large scale F-region electron temperature enhancements when heating close to the harmonics of the electron gyro frequencies, the persistence in the ion-line enhancement throughout the heater on periods during the experiment reported here, has made it impossible to confirm their results.

Acknowledgements. We thank the Director of EISCAT and his staff for operating the facility and the UK EISCAT Group for providing the software for data analysis. EISCAT is an association of the national scientific agencies of Finland, France, Germany, Japan, Norway, Sweden and the United Kingdom. Thanks are also due to CUTLASS PI (Mark Lester) and his colleagues for operating CUTLASS and supplying the data. CUTLASS is funded by the Particle Physics and Astronomy Research Council (PPARC) as one of the UK STP National Facilities.

Topical Editor D. Alcaydé thanks E. Mjølhus for his help in evaluating this paper.

\section{References}

Boiko, G. N., L. M. Erukhimov, V. A. Zyunin, G. P. Komrakov, S. A. Metelev, N. A. Mityakov, V. A. Nikonov, V. A. Ryzhov, Yu. V. Tokarev, and V. L. Frolov, Dynamic characteristics of stimulated radio emission from ionospheric plasma, Radiophys. Quantum Electron, 28, 259, 1985.

Dysthe, K. B., E. Mjølhus, H. L. Pecseli, and K. Rypdal, Thermal cavitons, Phys. Scr., T2/2, 548, 1982.

Greenwald, R. A., K. B. Baker, J. R. Dudeney, M. Pinnock, T. B. Jones, E. C. Thomas, J -P. Villian, J -C. Cerisier, C. Senior, C. Hanuise, R. D. Hunsucker, G. Sofko, J. Koehler, E. Nielsen, R. Pellinen, A. D. M. Walker, N. Sato, and H. Yamagishi, DARN/SuperDARN: A global view of the dynamics of highlatitude convection, Space Sci. Rev., 71, 761-796, 1995.
Gurevich, A. V., A. V. Lukyanov, and K. P. Zybin, Stationary striations developed in the ionospheric modification, Phys. Rev. Lett., 75, 2622, 1995.

Honary, F., A. J. Stocker, T. R. Robinson, T. B. Jones, and P. Stubbe, Ionospheric response to HF radio waves operating at frequencies close to the third harmonic of the electron gyrofrequency, J. Geophys Res., 100, 21489, 1995.

Jones, T. B., T. Robinson, H. Kopka, and P. Stubbe, Phase changes induced in a diagnostic radio wave passing through a heated region of the auroral ionosphere, J. Geophys. Res., 87, 1557$1564,1982$.

Jones, T. B., T. Robinson, P. Stubbe, and H. Kopka, A hysteresis effect in the generation of field-aligned irregularities by a highpower radio wave, Radio Sci., 18, 835, 1983.

Leyser, T. B., B. Thidé, H. Derblom, A. Hedberg, B. Lundborg, P. Stubbe, and H. Kopka, Stimulated electromagnetic emission near electron cyclotron harmonics in the ionosphere, Phys. Rev. Lett., 63, 1145, 1989.

Leyser, T. B., B. Thidé, H. Derblom, A. Hedberg, B. Lundborg, P. Stubbe, and H. Kopka, Dependence of stimulated electromagnetic emission on the ionosphere and the pump wave, J. Geophys. Res., 95, 17233, 1990.

Leyser, T. B., B. Thidé, M. Waldenvik, E. Veszelei, V. L. Frolov, S. M. Grach, and G. P. Komrakov, Downshifted maximum features in stimulated electromagnetic emission spectra, J. Geophys. Res., 99, 19555, 1994.

Mjølhus, E., On the small scale striation effect in ionosphere radio modification experiments near harmonics of the electron gyrofrequency, J. Atmos. Terr. Phys., 55, 9907, 1993.

Mjølhus, E., Parametric instabilities of trapped upper-hybrid oscillations, J. Plasma Phys., 58, 747, 1997.

Rietveld, M. T., H. Kohl, H. Kopka, and P. Stubbe, Introduction to ionospheric heating at Troms $\varnothing-1$. Experimental overview, J. Atmos. Terr. Phys., 55, 577-599, 1993.

Robinson, T. R., The heating of the high latitude ionosphere by high power radio waves, Phys. Rep., 179, 79-209, 1989.

Robinson, T. R., F. Honary, A. J. Stocker, T. B. Jones, and P. Stubbe, First EISCAT observations of F-region electron temperature during RF heating at harmonics of the electron gyrofrequency, J. Atmos. Terr. Phys., 58, 385-395, 1996.

Stocker, A. J., F. Honary, T. R. Robinson, T. B. Jones, and P. Stubbe, Anomalous absorption during artificial modification at harmonics of the electron gyrofrequency, J. Geophys. Res., 98, 13627, 1993.

Stubbe P., Review of ionospheric modification experiments at Tromsø, J. Atmos. Terr. Phys., 58, 349, 1996.

Stubbe, P., H. Kopka, B. Thidé, and H. Derblom, Stimulated electromagnetic emission: A new technique to study the parametric decay instability in the ionosphere, J. Geophys. Res., 89, 7523, 1984.

Stubbe, P., A. J. Stocker, F. Honary, T. R. Robinson, and T. B. Jones, Stimulated electromagnetic emissions and anomalous HF wave absorption near electron gyroharmonics., J. Geophys. Res., 99, 6233, 1994.

Thidé, B., H. Kopka, and P, Stubbe, Observations of stimulated scattering of a strong high-frequency radio wave in the ionosphere, Phys. Rev. Lett., 49, 1561, 1982.

Vaskov, V. V., and A. V. Gurevich, Amplification of resonant instability and generation of wideband radio emission by highpower radio waves incident on the ionosphere, Geomag. Aeron., 24, 350, 1984. 